\title{
Formation of the phosphate-resistant communities of microalgae and bacteria in the subpolar waters
}

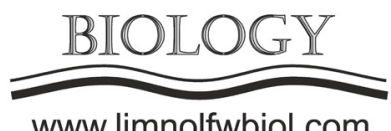

\author{
Kublanovskaya A.A.*, Zaytsev P.A., Chekanov K.A., Osipova A.A., \\ Solovchenko A.E., Lobakova E.S.
}

Faculty of Biology, Lomonosov Moscow State University, 1-12 Leninskie Gory, Moscow, Russia 119192

\begin{abstract}
The decrease of the available phosphorus reserves has a detrimental effect on agriculture and other industrial sectors. Various microorganisms are used in biotechnology for bioremoval of the inorganic phosphate from wastewaters, with the following application as biofertilizers for agricultural crops production. Both associations and monocultures of microalgae, cyanobacteria, and heterotrophic bacteria are able to accumulate high concentrations of phosphorus in their cells and are useful microorganisms for biotechnological phosphorus uptake. Communities of microorganisms formed in water bodies near tailing sites of the apatite mines were investigated. We studied the communities formed in the Lake Bolshaya Imandra (Murmansk Oblast, Karelia, Russia), in the tailing pond, as well as in a temporary pond ("puddle"); in total, five samples were studied. The morphological characteristics and the taxonomic composition of the samples were studied by light microscopy and DNA metabarcoding. Among bacteria, representatives of the phyla Proteobacteria, Firmicutes, and Actinobacteria were identified as dominants; bacteria of the phylum Bacteroidetes were less present. The results revealed a high degree of similarity of communities in terms of taxonomic structure at the genus level, which indicates the formation of common unique conditions in this region. The smallest variety was noted in the temporary "puddle" pond, which indicates less stability of the community formed in it.
\end{abstract}

Keywords: microbial communities, metabarcoding, microalgae, cyanobacteria, phosphorus uptake

\section{Introduction}

The exhaustion of the nutrients in the environment is one of the most serious ecological problems affecting the contemporary word. The most acute situation is with phosphorus, going out in high amounts from the natural cycle as a component of wastewaters. Screening of the microorganisms and their associations capable of effective phosphorus biosorbtion from the wastewater is a topical issue. We studied the natural communities of microorganisms forming in water bodies in the vicinity of the city of Apatity (Murmansk Oblast, Karelia, Russia), near the tailing ponds of the apatite-nepheline enrichment factory (ANOF-2). This habitat is characterized by a high content of inorganic phosphates and is promising as a source of the strains and microorganism associations applicable for the bioremoval of phosphates from wastewaters.

\section{Materials and methods}

Samples were collected in the vicinity of Apatity $\left(67^{\circ} 34^{\prime} 03^{\prime \prime} \mathrm{N}, 33^{\circ} 23^{\prime} 36^{\prime \prime} \mathrm{E}\right)$. Total of five samples were collected: (1) water from the coastline of the Lake
Bolshaya Imandra, (2) water from the backwater of Lake Bolshaya Imandra, (3) water from the tailings pond, (4) soil from the pond, (5) water from the temporary puddle. Morphological analysis of microorganisms was performed using a light microscope Leica DM 2500 (Leica, Germany) equipped with a digital camera Leica DFC 7000T of the same manufacturer. Environmental DNA was isolated using a MagJET Plant Genomic DNA Kit (Thermo Fisher Scientific, USA); bacteria were identified by metabarcoding based on the V4 hypervariable fragment of the gene of 16S rRNA; $16 \mathrm{~S}$ rRNA libraries preparation, sequencing, and metagenomic data analysis were conducted according to Kublanovskaya et al. (2020). For the description of eukaryotic components a previously described approach was used (Chekanov et al., 2019). Fragments of the samples were seeded into BG-11 (Stanier et al., 1971) media with increased content of phosphates (160 $\mathrm{mg}(\mathrm{P}) / \mathrm{L})$.

\section{Results and discussion}

Based on the microscopy data, a large number of eukaryotic microalgae (green and diatoms), as 
well as unicellular and trichomic cyanobacteria, were noted in the samples. Heterotrophic bacteria of various morphotypes were also present in samples in significant amounts. All the samples contained biofilms of various structural organization (according to Nikolaev and Plakunov, 2007), formed by cells and trichomes of eukaryotic microalgae and cyanobacteria, connected by an extracellular polymeric matrix. Active growth of the storage cultures was noted in the liquid mineral medium BG-11 with high phosphorus content. The highest taxonomic richness at the level of genera was detected in the samples of Lake Imandra and its backwash (54 and 53 genera, respectively) by DNA metabarcoding, while the lowest one was noted in the 'puddle' sample. Such a pattern indicates the temporary nature of the reservoir and the low stability of the communities formed in it (Stenuit and Agathos, 2015).

Based on the chloroplast DNA sequences analysis, the diversity of eukaryotic microalgae was described, among which green Chlorella-like microalgae were most abundant. These microalgae were observed by microscopic observations in the corresponding community samples.

\section{Conclusions}

Biotechnologically promising environmental communities of algae and bacteria formed in habitats with a high phosphate content were studied. A limited number of eukaryotic microalgae and more diverse representatives of cyanobacteria have been identified. Microscopic data on microorganism diversity were in accordance with the DNA metabarcoding data regarding similar diversity of eukaryotic phototrophic microorganisms. The active growth of microorganisms on the medium with a high content of phosphates indicates the prospect of obtaining the strains from them that can survive in such conditions and accumulate phosphates. Characterization of the taxonomic composition of the samples is the first step for the isolation of the strains of eukaryotic microalgae, cyanobacteria and heterotrophic bacteria, as well as their associations for further biotechnological research.

\section{Acknowledgments}

Funding by Russian Foundation for Basic Research (grant 18-29-25050) is gratefully appreciated.

\section{References}

Chekanov K., Kublanovskaya A., Lobakova E. 2019. Eukaryotic sequences in the 16S rRNA metagenomic dataset of algal-bacterial consortia of the White Sea coastal zone. Journal of Eukaryotic Microbiology 66: 853-856. DOI: 10.1111/jeu.12722

Kublanovskaya A., Solovchenko A., Fedorenko T. et al. 2020. Natural communities of carotenogenic chlorophyte Haematococcus lacustris and bacteria from the White Sea coastal rock ponds. Microbial Ecology 79: 785-800. DOI: 10.1007/s00248-019-01437-0

Nikolaev Y.A., Plakunov V.K. 2007. Biofilm "City of microbes" or an analogue of multicellular organisms? Microbiology 76: 125-138. DOI: 10.1134/ S0026261707020014

Stanier R.Y., Kunisawa R., Mandel M. et al. 1971. Purification and properties of unicellular blue-green algae (order Chroococcales). Bacteriological Reviews 35: 171-205.

Stenuit B., Agathos S.N. 2015. Deciphering microbial community robustness through synthetic ecology and molecular systems synecology. Current Opinion in Biotechnology 33: 305-317. DOI: 10.1016/j. copbio.2015.03.012 